\section{Memórias de Pesquisa}

Professor do Dep./UnB; coordenado PPGSOL/UnB; tutor PET/SOL/UnB.

Graduanda SOL/UnB

Graduando SOL/UnB

Graduanda SOL/UnB.

Graduando SOL/UnB

\title{
Arte com Ciência: a propósito de futuros (pós)existentes na arte de Patricia Piccinini
}

\author{
Fabrício Neves ${ }^{*}$, Alane Nóbrega ${ }^{* *}$, Guilherme Gomes ${ }^{* * *}$, Luana Marinho ${ }^{* * * *}$, Pedro Momag ${ }^{* * * * *}$
}

\section{Introdução}

A exposição "COMCIÊNCIA” da artista plástica australiana Patrícia Piccinini, com curadoria de Marcello Dantas, estreou no Brasil em 2015, em várias capitais, envolta em controvérsias. Se para muitas as obras seriam uma atualização das grandes obras em mármore dos grandes artistas gregos e renascentistas, para outros seriam nada mais que sensacionalismo barato produzido à custa da curiosidade pelo grotesco e bizarro. A ambivalência aqui não é só atribuída à crítica, é também aos sentimentos opostos que as obras despertam nos expectadores. Isso, devido ao uso da técnica que junta ficção e ciência, imaginação e hiper-realidade, confundindo mundos diferentes, apontando, no presente, para realidades futuras já admitidas como possíveis na qual nossos sistemas de classificação seriam completamente confundidos aos auspícios da genética.
Este texto surgiu a partir de uma disciplina de verão, da Graduação em Ciências Sociais, da Universidade de Brasília. A disciplina em questão, sociologia do conhecimento, relacionava o conhecimento, a ciência e tecnologia a outras formas de vida, mostrando seus impactos societais e a maneira como a sociedade influenciava o conteúdo e a forma da dinâmica cognitiva. O que mais nos interessava era encontrar o social no cognitivo, atentando para a maneira como na prática construímos a sociedade e o conhecimento concomitantemente.

No decorrer da disciplina nos deparamos com a construção do conhecimento na vida cotidiana, dos saberes tradicionais, das biotecnologias, do racismo científico, entre outras formas de relação entre ciência e sociedade. Coincidiu também da exposição de Patrícia Piccinini estar em Brasília naquele momento. Este texto surgiu então da discussão da relação entre arte e ciência, melhor dizendo, das maneiras como a ciência influencia a imaginação 
artística. Ele incorpora, a partir dessa premissa, nossa experiência com a obra artística em questão e nossa reflexão em sociologia do conhecimento.

\section{Artes e ciência}

A exposição traz antigas relações entre arte e ciência, nas quais as criações humanas por meio da ciência voltar-se-iam contra ela, ao sair do seu controle. Tais narrativas ficcionais são encontradas desde o conto do Golen, achando mais recentemente terreno na literatura de ficção científica e no cinema. No entanto, Patrícia inverte a correlação e chega a destacar, por vezes, relações harmônicas entre criadoras e criaturas, ou até mostrando como criaturas serviriam aos humanos, incorporando funções de entretenimento e amamentação. Neste terreno familiar no qual as obras são instaladas, os sentimentos de repulsa e medo de seres por vezes bizarros se transformam em sentimentos de afeto $\mathrm{e}$ compaixão, humanizando-os. Leva-nos assim a pensar em futuros possíveis para a relação entre humanos, animais e vegetais, numa mescla (harmônica?) do que se conhece como vida. Não seria esta também a função da obra de arte?

De modo análogo ao que alguns cientistas sociais fizeram a partir de fins do século XX - como as antropólogas Emily Martin e Donna Haraway -, os seres de Patricia questionam a objetividade e essencialidade subjacentes (e ocultas) nas categorias, nas divisas sociocientíficas do "natural" e do "humano". Até que ponto os alimentos transgênicos, sobretudo aqueles desprovidos da capacidade de reprodução, são do Reino Plantae? Por que colocamos com tanta "naturalidade" aquelas "anomalias" à mesa? Até que medida as inúmeras próteses que incorporamos aos nossos corpos, principalmente na atual era da "internet of things", nos aproximam do que antes considerávamos como não-humanos? Qual paradigma nos orienta na classificação das entidades criadas por intervenção biotecnológica? Por que "seres" modificados geneticamente seriam menos "seres" que aqueles gerados por um modo de reprodução "natural"? Por que consideramos mutações genéticas como processos "naturais" cujos produtos são "não naturais"? Por que insistimos na normatividade imutável do "natural”, enquanto "o mundo da vida" está em constante processo de mudança?

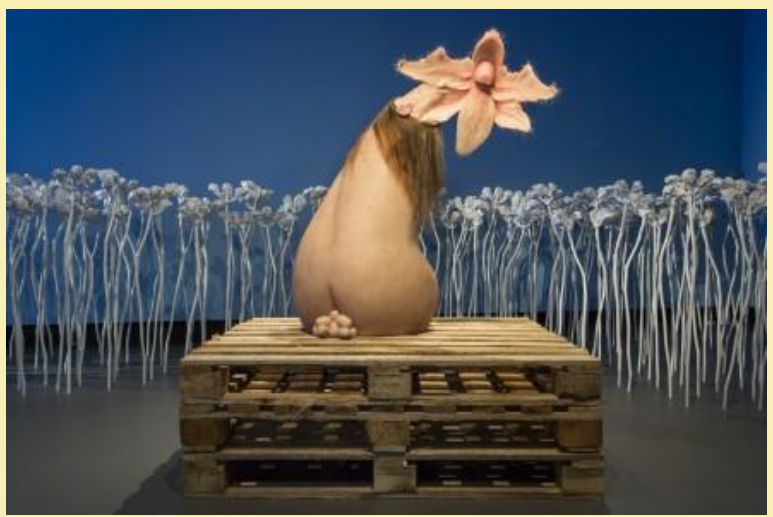

Figure 1 Flor Bota - Patrícia Piccinini 
${ }^{1}$ Sobre técnicas hiper-realistas na arte, nos afirma a artista: "As preocupações conceituais de Hiper-realismo, que parecem ser em grande parte formais, não encontram nenhuma ressonância em mim. Isso talvez pareça pouco sincero, dado que muitos de meus trabalhos utilizam técnicas da produção hiperrealista. No entanto, essas técnicas de produção são apenas isso: processos de fabricação que são os meios para atingir um fim, ou seja, para comunicar uma ideia" (DANTAS, 2015, pág. 23).
A exposição nos conduz ao confronto com um complexo conjunto de questões cujo cerne se encontra na problematização da relação entre arte e ciência; nas convenções sociais sobre padrões estéticos; no etnocentrismo; no cientificismo/naturalismo; no contato muitas vezes conflituoso com a alteridade; nas tendências tecnocientíficas contemporâneas (sobretudo quanto aos feitos da biotecnologia e da inteligência artificial). Ademais, sem esgotar o escopo meditativo, as "esquisistas criaturas" hiper-realistas ${ }^{1}$ de Patrícia estimulam inquirições de caráter epistemo-ontológico, no que diz respeito a novas formas de seres ou de "ser", ou seja, à linha que arbitraria e transitoriamente divide a "natureza" da "cultura", os "humanos" dos "não-humanos", o "eu” do "outro".

Provocando a suspensão de juízos pré-estabelecidos quanto ao que é "naturalmente humano", sobretudo em um horizonte social em que a mútua interação entre sociedade e tecnologia tende a tornar-se cada vez mais intensa, a artista nos apresenta obras criadas com materiais sintéticos: simulacros de possíveis "seres" (em oposição a meras “coisas"), produtos de experimentações biotecnológicas. Nesse processo mimético, a "artificialidade" se funda à "naturalidade". Em uma audaciosa provocação, a artista nos intima à reflexão sobre as limitações dos conceitos de "entidades naturais", "aberrações", "anomalias" e "máquinas/coisas" conceitos esses fundamentados em convenções sociais, porém desafiados pelas características "anímicas" e "humanas" daquelas “criaturas". Dotadas de sentimentos e de capacidade de expressálos, as criaturas outrora sintéticas se tornam também criadoras.

Desse modo, a observação daquelas "estranhas criaturas" culmina também no confronto mimético com nosso devir, com o devir de nossas "criações" e com nossa cosmologia. A artista parece querer nos retirar do conforto das classificações habituais, seguras e "naturalizadas" para nos colocar diante do silencioso (tácito) mecanismo de ordenação do nosso mundo. As entidades da artista nos apresentam um mundo povoado por novos "seres", mas tributário das representações, interações, valores e normas sociais convencionais: hierárquicas, racistas, machistas. O que nos faz pensar que a ciência, longe de oferecer ruptura com nossas mazelas, pode reproduzi-las em novas roupagens.

\section{Ciência como lócus eugênico}

É inescapável na obra "A grande mãe", por exemplo, a estreita relação entre os discursos científicos de cunho eugenista e as diversas modalidades de racismo desenvolvidas na história humana, considerando-se as relações sociais entre as "mães pretas" ou "amas de leite" dos períodos escravocrata e pós-abolição no Brasil e em outros lugares do mundo. 
${ }^{2}$ Sobre o feminino na arte, nos fala a artista: "O feminino constitui a realidade para mais da metade das pessoas no mundo, mas no mundo da arte, é muito difícil de encontrar. Quando você de fato o vê, é muitas vezes considerado como " "alternativo" ou "de nicho", um pouco estranho ou indecoroso como um tema para a arte. Penso que assuntos como sexualidade e família são cruciais" (DANTAS, 2015, pág. 23).

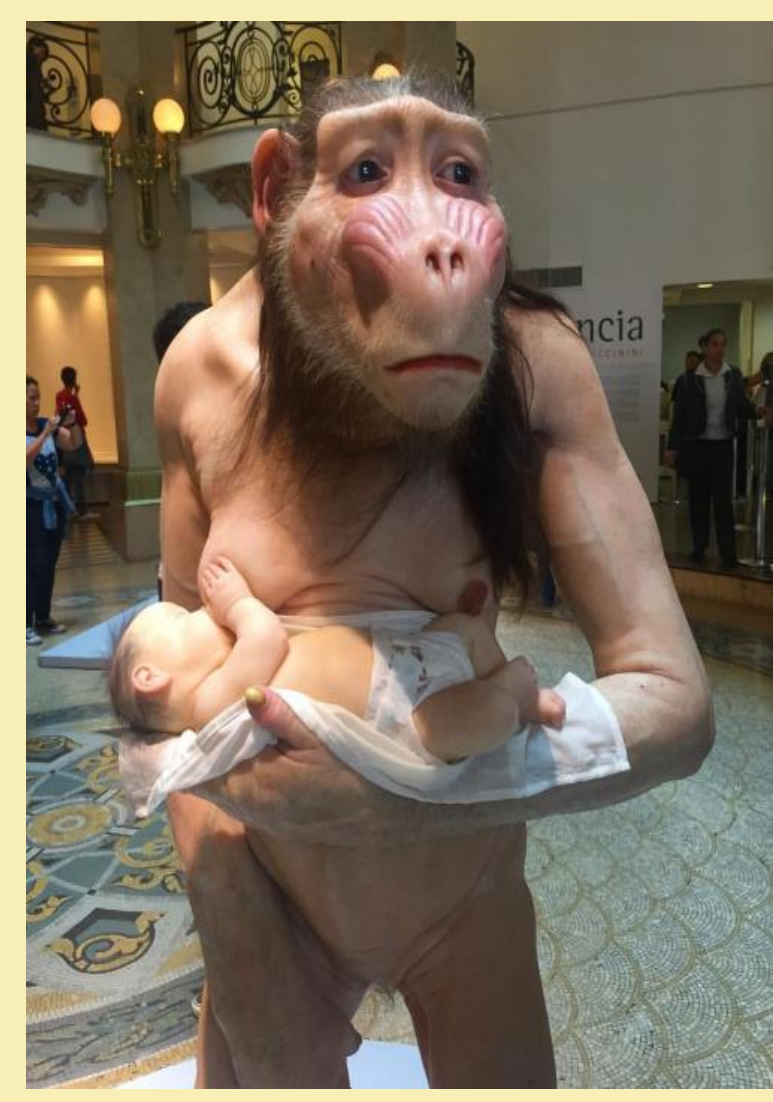

Figure 2 A grande mãe - Patrícia Piccinini

A fêmea, com feições de primata alimenta um bebê humano. $\mathrm{O}$ fato de o bebê estar vestido com fralda, bem como os demais seres humanos retratados ao longo da exposição, e a ama de leite estar despida, insinua que apesar de todos os seres ali serem humanizados e da possibilidade de intercâmbio de atividades, eles são diferentemente considerados. Talvez no contexto de origem da autora, essa obra sugira uma grande mudança nas atribuições sociais dos indivíduos que compõem o núcleo familiar. No caso brasileiro é possível conceber a ideia de permanência ou de retorno a relações sociais marcadas pela figura feminina, cuidadora e presente no cotidiano familiar que, no entanto, não goza de status de igualdade em relação àqueles a quem serve.

Confome Llana Lowy (2008), a ideia do objetivo da constituição biológica é uma construção social, depende das concepções construídas e, como tal, detêm a possibilidade de correção e desconstrução. Visto que as mulheres têm sofrido grande interferência da ciência, principalmente a partir do século XX, tendo seus corpos mutilados e alterados frequentemente, seja por interferências cirúrgicas ou mesmo por "readequações" hormonais, a exposição ressalta que estas intervenções poderiam ser reproduzidas pelos tais seres "engenheirados", para que tudo continue como está. Embora a dinâmica científica seja potencialmente capaz de modificar a imagem da mulher na sociedade, a forma como elas se veem perante o mundo ao desempenhar seus papeis sociais preestabelecidos, assim como a forma como se veem perante a velhice e a ideia de inadequação ou inutilidade, nada garante que a ciência, masculina em sua estrutura, romperia sua sina de controle do corpo feminino ${ }^{2}$.

A inércia da reprodução dos valores hegemônicos valeria também, como se vê na exposição, para o ideal de beleza. Na obra "A confortadora", observa-se que em um mundo em que não há 
estranheza quanto a animais de fisionomia e fisiologia tão diferentes dos do nosso mundo, é possível a ampliação do que é considerado normal e saudável também para seres humanos que, em nosso mundo, são considerados anormais. A menina, humana, é portadora de uma condição genética denominada hipertricose, que provoca o desenvolvimento de muitos pelos por todas as partes do corpo. $\mathrm{Na}$ realidade atual, em que impera um ideal de beleza ocidental, a hipertricose é vista como anormal, digna de tratamento e investimentos estéticos, a despeito de não afetar o funcionamento do organismo.

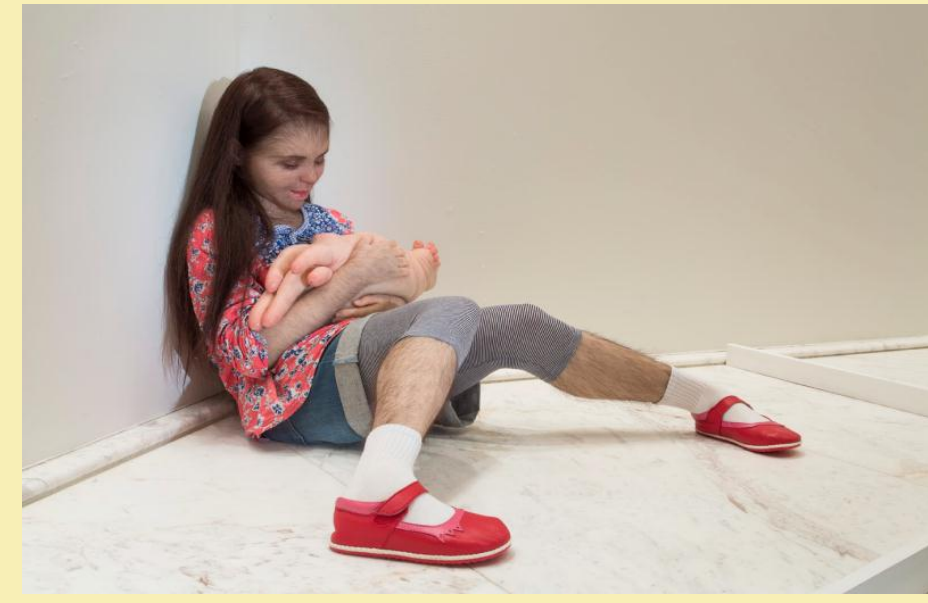

Figure 3 A confortadora - Patrícia Piccinin

A hipertricose ilustra bem que, algumas das condições físicas consideradas anormais e medicalizadas dizem mais respeito a designações sociais sobre o que é ou não considerado aceitável e menos sobre o que de fato compromete o funcionamento dos organismos. Se as figuras anteriores sugerem relações sociais favoráveis, talvez previstas e planejadas nos processos de experimentação e criação dos seres apresentados, outras figuras apresentam a autonomia desses mesmos seres em relação a sua programação original. Assim como os seres humanos que fazem muito mais que nascer-crescer-reproduzir-morrer, alguns deles são dotados de intencionalidade, curiosidade e necessidade de conhecer.

\section{(Trans) corporalidades}

Assim, as criaturas criadas por Patrícia Piccinni desafiam a corporalidade esperada de um ser humano. São, poderia se dizer, monstruosidades. Uma discussão quanto à categoria de monstro cabe aqui: monstro enquanto algo que foge do ordenamento conhecido cotidianamente, um desvio, uma encarnação do misterioso. Assinalando as características fundamentais da monstruosidade, Jorge Leite Júnior (2012) propõe uma discussão acerca do assunto, nos apresentando o monstro enquanto uma categoria de pensamento capaz de orientar a conduta em direção à normalidade, por meio do discernimento comparativo feito em relação ao outro desviante, ao ente que causa repulsa devido à sua incompreensibilidade. 
O monstro é por excelência a manifestação de algo fora da ordem, operando no limite de categorias. Ainda que seja inteligível socialmente, o monstro sempre carrega em seu corpo algo diverso daquilo que é esperado ou não normativamente previsto. Por sua vez, essa distorção da normalidade pode vir a causar o não reconhecimento de si em uma figura, causando estranhamento algo que não falta em uma exposição que se preocupa com a exaltação de modificações genéticas.

As criações de Piccinni, entretanto, seguem uma direção contrária daquela dos monstros tratados por Jorge Leite Júnior (2012), que se preocupa principalmente com o tratamento de pessoas desafiadoras de normas corporais hegemônicas, tal como pessoas trans. $\mathrm{O}$ autor descreve, se referindo à resposta cultural aos monstros:

(...) ao encará-las como o equivalente ao Mal e ao caos, a única ação ou reação socialmente inteligível é a destruição ou $\mathrm{o}$ anulamento (literais ou simbólicos) dessas pessoas. O monstro não é apenas uma domesticação do abjeto, mas sua organização como uma categoria específica que legitima tanto a atração quanto a destruição ou punição do sujeito sobre o qual recai essa mesma atração. (LEITE JÙNIOR, 2012, p.563)

As obras presentes na exposição não transpassam qualquer desejo de animosidade ou de aniquilação da parte do observador, ainda que causem desconforto. São tratadas, ao contrário, como criaturas que, em toda a sua diferença e provocação, sentem e são capazes de afeto, não sendo algum alvo de nojo ou repulsa. Seria possível aderir a uma proposta de atenuação da diferença do outro ao se encontrarem elementos de nível emocional em comum entre o observador e o objeto estranho, como o desejo de afeto, e o apego.

Prazer, dor e desejo às vezes ocorrem, mas as reações ao trabalho de Piccinini são, mais frequentemente, uma combinação dessas assim chamadas emoções primárias, ambivalência é o resultado. A ambivalência em relação ao mundo de Piccinini reflete, em parte, uma ambivalência geral na sociedade contemporânea em relação à proliferação de novas tecnologias (MCDONALD, 2015, pág. 29-30).

\section{Tradução: Arte e cotidiano}

A reflexão quanto ao envolvimento do conhecimento científico e novas tecnologias com o conhecimento cotidiano, pode ser aprofundada com a proposta de Berger e Luckmann (1974). Estes autores trazem à tona o conceito de mundo da vida - uma instância preenchida de interações e de laços intersubjetivos, uma realidade herdada e cotidiana, que promove um estoque de conhecimentos socialmente construídos, esses diretamente influenciando pelo processo de socialização de indivíduos. Expostas em um cotidiano (ainda que em um centro cultural), as obras de Piccinni encontra acolhida por conta da rapidez na qual pessoas tem incorporado, em seu cotidiano, mudanças corporais e se envolvido cada vez mais com tecnologias antes desconhecidas, que vêm a 
mudar a maneira na qual as interações face a face se comportam. Ou seja, vive-se uma época na qual a estrutura fenomenológica do tempo da vida cotidiana assume a rapidez das transformações tecnocientíficas, lançando a imaginação a um exercício de expectativa que normaliza estranhamentos e o imprevisto acaba por estar previsto. $\mathrm{Na}$ arte ou na ciência.

Este estoque cotidiano de conhecimento prévio nos leva, no entanto, a uma tentativa de classificação do que está sendo observado, o que propõe a sistematização de conceitos adquiridos por meio de diferentes tipos de conhecimentos, cotidiano e científico, para melhor explicar e traduzir o que está diante de suas percepções. Isso porque, além da relação feita com alguns animais, essas obras também apresentam características desconhecidas e não classificáveis dentro desse conjunto de conceitos assimilados.

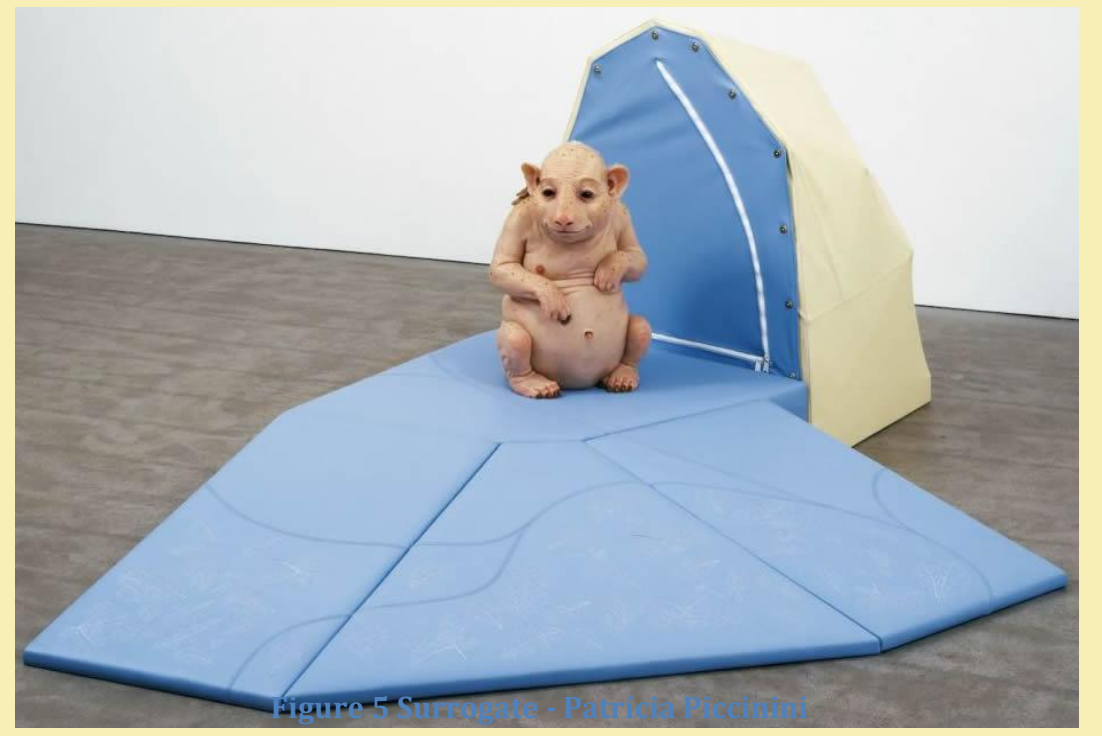

Dossiê Multimodalidade da Memória: Narrativa e Teoria Social

Arquivos do CMD, Volume 4, N.1. Jan/Jun 2016
Um exemplo, é a escultura "Surrogate" (2005, "Substituto"), na tentativa de interpretá-la, é possível que algumas pessoas digam que a criatura se parece com algum tipo de animal, mas que, também, apresenta aspectos não reconhecíveis. O exercício de classificação e de descrição dessa criação é algo bem difícil, já que ela não se enquadra a um aspecto totalmente pertencente a um único ser. Contudo, é algo que permite desligar-se de conceitos préadquiridos para propor uma dinâmica interpretativa a partir de novas concepções. Nas costas do "Surrogate" existem seis bolsas nas quais estão um tipo de animal indígena típico da Austrália, em três diferentes fases, popularmente conhecido como "wombat-de-narizpeludo-do-norte" (Lasiorhinus), o qual está ameaçado de extinção.

Nessa obra, a proposta da artista não foi apenas colocar em

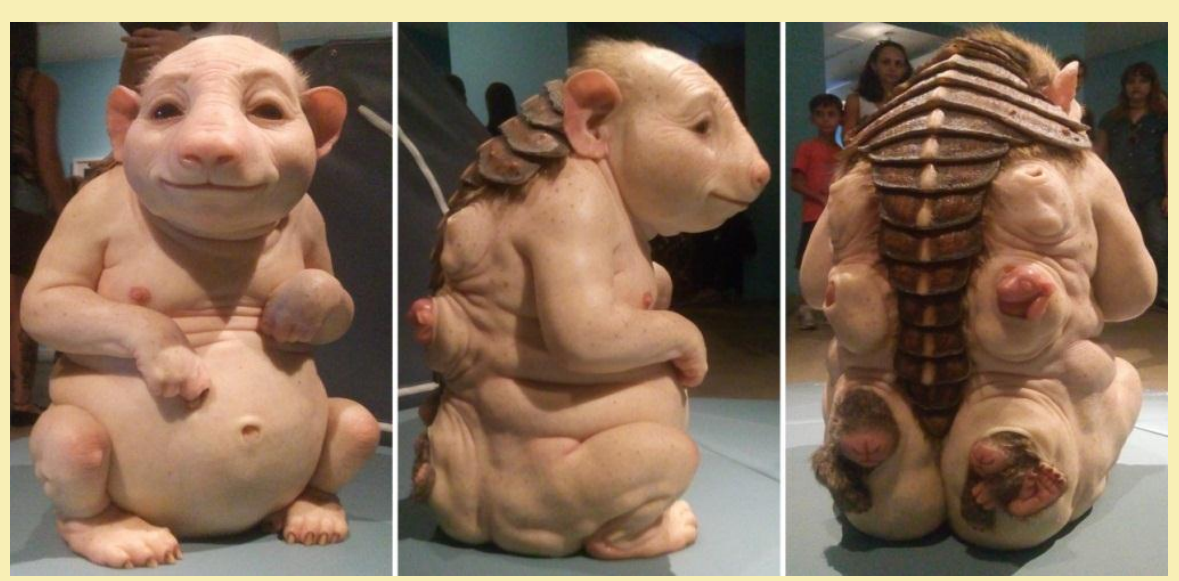

debate a questão da extinção, mas fazer um anacronismo com o

Figure 4 Surrogate - Patrícia Piccinin 
universo das tecnologias biomédicas, ao apresentar o animal numa tenda azul, abrigo fora de seu habitat natural. No sul da Austrália, cientistas têm utilizado tecnologias de reprodução assistida para conservação de wombat-de-nariz-peludo-do-sul, ou seja, ao invés de criar-se tecnologias que permitam a reprodução natural, o processo tem sido realizado em laboratório. Dessa forma, Piccinni prevê o mesmo futuro para a espécie do norte. Além disso, o nome da obra significa "substituto", o que pode ser entendido pela perspectiva de troca do natural pelo artificial.

\section{Inclassificáveis}

Questões sobre sistemas de classificação emergem ao longo da exposição, principalmente envolvendo os limites entre humanos e não humanos. Na obra "The Long Awaited" (2008, "O tão esperado"), a artista procura demonstrar uma relação de afeto entre um garoto e uma idosa, o que parece ser uma espécie de peixe-boi ou vaca-marinha com forma humana.

This is the definition, I think, of real love: you allow someone to nurture you and love you. In this situation we see a boy and an older woman who probably aren't related, but they have this physical connection. They have probably more of a spiritual or soulful connection in that she is allowing him to look after her as much as she's probably looked after him and nurtured him, because children need to be nurtured (PICCININI, 2012).

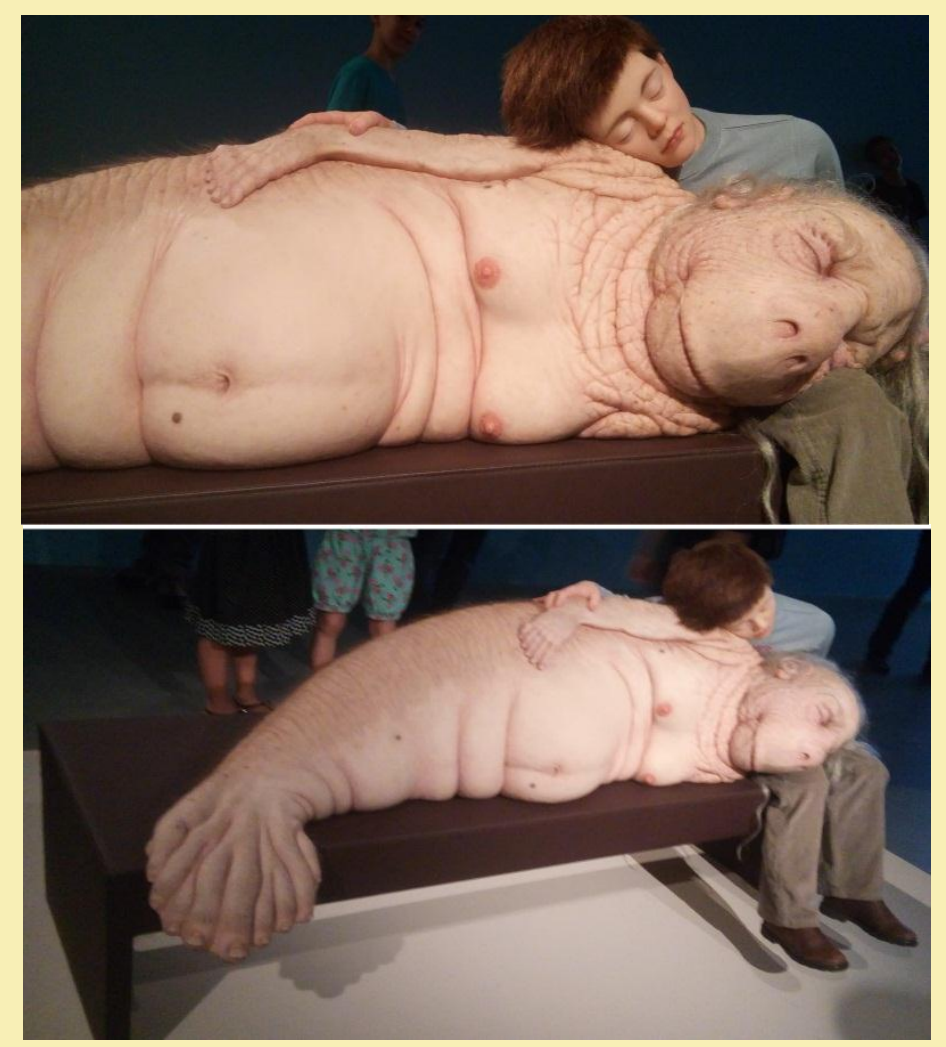

Figure 6 The long awaited - Patrícia Piccinini

Piccinini escolheu o dugongo ou peixe-boi como inspiração na obra, pelo fato de estar sob ameaça de extinção e porque ela percebe traços humanos na espécie, ao notar alguma semelhança com as sereias, seres míticos que mesclam o humano com um ser marinho. Ela demonstra nessa criação a possibilidade de uma 
3 "Children connect things that are foreign in a way that adults can't because we've grown up with all these ideas about ourselves that inform the way we can now treat other animals, and children haven't learned those ideas yet". relação afetuosa e pacífica entre diferentes espécies, entre humanos e não humanos. Além disso, propositalmente foi escolhida uma criança para interagir com a criatura, pois às pessoas adultas são impostos conhecimentos, crenças e formas de pensar que em crianças ainda estão em construção. Piccinini (2012) sugere que "crianças relacionam coisas que são estranhas de uma maneira que os adultos não podem fazer, por que cresceram com ideias sobre si mesmos as quais informam a maneira de tratar outros animais. As crianças não aprenderam estas ideias ainda"”3. Assim, à criança é facilitada a aceitação do que é estranho, sem que haja alguma tentativa de classificação prévia.

As crianças aparecem com frequência no mundo de Piccinini, e aceitam as criaturas mutantes que encontram como algo natural e parte da vida. Se seu mundo nos parece estranho e distorcido, talvez seja porque não tenhamos crescido nele (MCDONALD, 2015, pág. 31).

Para nós, não é possível nomear aqueles seres. Eles estão fora de nossos sistemas de classificação, sendo, reconhecidos pela hibridez que os compõem geneticamente. Classificar esses seres implica, em alguma medida, padroniza-los. Ou seja, eleger as características que reconhecemos como definidoras de sua singularidade. Jasanoff (2012) demonstra que um dos recursos da construção de "impérios" - não somente impérios políticos, mas também a ciência ocidental, como império epistemológico - e de exercício da dominação, consiste na padronização das coisas. A eugenia, por exemplo, consiste na padronização dos corpos humanos de acordo com uma ideologia cientificamente sustentada sobre a superioridade de alguns humanos em relação a outros

Sendo assim, em uma sociedade cujos sistemas de classificação contemplam esses seres geneticamente modificados, talvez eles não mais sejam reconhecidos como híbridos, mas como seres singulares e com uma identidade definida. Ou seja, a criação desses seres não seria finalizada nos procedimentos de manipulação genética em laboratórios. Sua criação seria desenvolvida também nas interações sociais e nos lugares atribuídos a eles nas estruturas e processos sociais. Conhecê-los, portanto, diz respeito não somente a reconhecer suas características físicas, mas conceber seu lugar nas redes de relações sociais.

\section{Referências Bibliográficas}

BERGER, Peter e LUCKMANN, Thomas. A Construção Social da Realidade. Petrópolis: Vozes, 1974

DANTAS, Marcelo. "Marcello Dantas entrevista Patricia Piccinini"' IN: DANTAS, Marcelo. ComCiência, Patricia Piccinini. Marcello Dantas. MaG+, São Paulo: 2015.

JASANOFF, Sheila. "Biotecnologia e império: o poder global das sementes e da ciência" IN: MARQUES, Ivan da Costa et al. Sheila Jasanoff: localizando o global. Rio de Janeiro, História, Ciências, Saúde - Manguinhos, v.19, n.3, jul.-set. 2012, p.993-1039.

LEITE JUNIOR, Jorge. "Transitar para onde?: monstruosidade, (des)patologização, (in)segurança social e identidades transgêneras". Rev. Estudos Feministas [online]. 2012, vol.20, n.2, 
pp. 559-568. Disponível em:

<http://www.scielo.br/scielo.php?script=sci_arttext\&pid=S0104-

026X2012000200016\&lng=en\&nrm=iso>.

LOWY, Llana. "Gênero e ciência" IN: NUNES, João; ROQUE,

Ricardo. Objetos Impuros: experiências em estudos sobre a ciência.

Porto: Edições Afrontamento, 2008.

MCDONALD, Helen. "Paradoxo e Imersão" IN: DANTAS,

Marcelo. ComCiência, Patricia Piccinini. Marcello Dantas. MaG+,

São Paulo: 2015.

PICCININI, Patrícia. "A talk with artist Patricia Piccinini, whose disquieting yet appealing works explore the bond between man and animal - The Long Awaited". Abril, 2012. Entrevistador:
IRELAND,$$
\text { Perrin. }
$$

$$
\text { Disponível }
$$
em:

http://www.nashvillescene.com/nashville/a-talk-with-artist-patricia-

piccinini-whose-disquieting-yet-appealing-works-explore-the-bondbetween-man-and-animal/Content?oid=2837945. Acessado em 04 de fevereiro de 2016. 